\title{
The Right to Preschool Education in São Tomé and Príncipe: Dilemmas and Challenges in the Conception of a Legal
}

\section{Framework}

\author{
Teresa Sarmento, Emília Vilarinho \\ University of Minho, Braga, Portugal
}

\begin{abstract}
This paper falls within the work of cooperation with the government of São Tomé and Príncipe and with the United Nations International Children's Emergency Fund (UNICEF), whose purpose is to create the Preschool Education Act and the Statutes of Education Institutions operating in the same level of education. The complexity and the relevance of this work to the present and future of the children of São Tomé and Príncipe demand from us a huge responsibility concerning its realization and a critic surveillance regarding the potential effects of "contamination" with transfrontier political guidelines and of "policy borrowings," which do not have into consideration the realities of the country, its cultures, its different social conditions and conceptions of childhood and of family, and its different patterns of organization and of intrafamily relationships. We adopted, in our approach to this project, the starting point, theoretically and ethically grounded, that it was necessary to free ourselves of a adultcentric point of view of childhood and of apriorisms that are stuck to the image of the country. Our analysis centers on two dimensions: (1) On the dilemmas that we face in the task of conceiving the "policies" of child education to the child population of an African country, in our condition of European researchers and teachers; and (2) In the process of shared making of that legal framework, focused on the realities of the country, especially on childhood, family, women, and labor conditions. A debate is going on about the proposed solutions that have been suggested, which, in an articulate fashion, respect children's right to education and leisure, value children's experiences, and attend the interests of families and of the community development.
\end{abstract}

Keywords: preschool education, children’s rights, educational policies, cooperation

\section{Introduction}

This paper falls within the work of cooperation with the government of São Tomé and Príncipe and with the United Nations International Children's Emergency Fund (UNICEF), whose purpose is to create the Preschool Education Act and the Statutes of Education Institutions operating in the same level of education. Its goals are identifying the dilemmas we are faced with, when we idealize policies for child education directed to the children of an African country, in our quality of European researchers and teachers; reflecting on the shared making of this legal framework, with a focus on the realities of the country, especially on the living conditions of children,

Teresa Sarmento, Ph.D., assistant teacher and researcher, Institute of Education, Research Centre on Child Studies (CIEC), University of Minho.

Emília Vilarinho, Ph.D., assistant teacher and researcher, Institute of Education, Research Centre in Education (CIED), University of Minho. 
families, women, and of labor, and discussing the solutions that have been forwarded, which, in an articulate way, respect children's right to education and leisure, value children's experiences, and attend the interests of families and of the development of the community.

The right of the children of São Tomé and Príncipe to education, to culture, and to protection are warranted in the Educational System Act (Act No. 2/2003-LBSE) ${ }^{1}$, which is the cornerstone that sustains the proposal of a Preschool Education Act. It is up to state institutions, thus, to find the ways to warrant the access (and success) of all the children of São Tomé and Príncipe to a system that respects these rights, and that fosters a set of social-psycho-pedagogical goals that effectively create the conditions favorable to full personal development of every children. The assurance regarding the implementation and use of this (those) right(s) with children aged from zero to six years old, implies making universal a system of preschool education that attends the needs of the individual, social, and geographical diversity of the children of São Tomé and Príncipe. The Constitution of São Tomé and Príncipe also prescribes that the education of children, within a structured educational system, whose responsibility the State ought to assume, should be developed in a articulate way with the values and beliefs of São Tomé and Príncipe and in collaboration with the families.

The general methodology we adopted to achieve the goals of the protocol consisted on the analysis of the literature, on the observation of missions in the field, and on the realization of "focus group" with different entities. Subsequently, we materialized the staged drafting of documents, which were successively evaluated by the local educational agents. During the development of this paper, we shall detail some of the different stages of this process.

Based on the goals previously outlined, we shall begin by identifying the dilemmas that we are faced with in the task of achieving a legal regulation, which puts in writing the respect for the rights of the children of São Tomé and Príncipe, and is regardful and preventive of the risks of contamination from deterritorialized ideologies and policies. Next, we shall present the dynamics developed in the course of this process, and in the end of the paper, we shall perform a final evaluation of the missions realized.

\section{Dilemmas in the Cooperation Process}

With the presuppositions enumerated in the previous paragraph as our starting point, we were charged of the challenging task of preparing the draft of the Preschool Education Act, as well as the draft of the Statutes of the Preschool Education Institutions.

Upon our acceptance of the making of these references for a policy of education for an African country, we were immediately faced with a set of dilemmas, explicitly enunciated, which we tried to resolve along the whole process: as trained teachers and researchers, with an already lengthy professional trajectory, which was developed in Europe: How could we make these legal instruments, simultaneously respecting the (existing and emerging) conditions of an African country? Contaminated with Eurocentric conceptions of educational policies, as we were, how could we achieve a state of critic decentration? Familiar with, and producers of, sociological and pedagogical research in a reality common to countries with a high level of development, how could we see, and propose the betterment of, child education in a so-called "peripheral" country, respecting its emerging process of development?

\footnotetext{
${ }^{1}$ Law-Educational System Act No. 2/2003.
} 


\section{Processes of Globalization and Transnationalization of Educational Policies}

Reflecting on preschool education for this African country compels us, from the very beginning, to be aware that we start from conceptions of educational policies integrated in a globalization process, characterized by transfrontier processes, and by a "hegemony of the North" (Santos, 2004; 2010), in other words, through which the ways of thinking of the North hemisphere seeks to impose its influence over the South hemisphere. Our being aware that these has been contamination "and borrowing effects of policies" (Walford, 2001; Barroso, 2003), in the process of definition of those policies, often in an uncritically fashion, has kept us permanently vigilant, seeking to avoid the reproduction of production practices which are alien to local realities. Thus, we recognize how important it is to be aware of the "influence context" and of the "policy production context" (Bowe, Ball, \& Gold, 1992) in the process of elaboration of legal documents, in a way that allows us to try to be vigilant and critical in the process of making proposals for these drafts.

Our stance follows the lead of post-colonial studies, which seek to present a critical analysis, grounded in a theory that calls into question the determinism of an European, Westerncentric standpoint (Sanches, 2012), that has been imposed to the so-called peripheral countries. Post-colonial studies warn us, and at the same time, challenge us, since our knowledge is formed in the North; these are our references, of which we need to decenter ourselves, in order for us to get to know, and give a contribution to the making of policies that legitimize the knowledges, the feelings, and the interests of Africans.

Supported on a line of thinking of a critical education, of an education to foster emancipation, and attentive to the words of Bourdieu and Passeron (1978), which make us aware that "the excluded ones reproduce their own exclusion," we seek to deconstruct the Eurocentric discourse, discussing it with the local actors, so as to be able to define the role of education in the lives of the children of São Tomé and Príncipe. In this African country, several international organizations (Organisation for Economic Co-operation and Development (OECD), UNICEF, World Bank, among others) are actively working, and we ought to know their actions, and especially, their underlying conceptions. Although we recognize the relevance of these organizations to the development of São Tomé and Príncipe, we assumed the task of getting to know the extension of the influence of these organizations in the lives of the children of this country, as well as the "contamination and borrowing of transnational policies effects” they bring to the society of São Tomé and Príncipe (Walford, 2001; Barroso, 2003).

\section{The Conceptions of Childhood and of Preschool Education}

Other set of dilemmas that we face are related with the target audience of the policies of preschool education, namely, the children. Our starting points are social studies on childhood, especially the ones on sociology of childhood, on policies on childhood, and on childhood education.

Sociology of childhood, in its theoretical, structuralist, interpretative, and critical guidances (for example, from the contributions of Qvortrup, 1991; 2010; James, Jenks, \& Prout, 1998; Prout, 2010; Corsaro, 1997; Sarmento, 2013), urges us to take into consideration, in the elaboration of educational policies, the structural conditions that characterize childhood in this country, as well as the children with their idiosyncrasies and their cultures. We are aware of the fact that there are conceptions of preschool education that are yet considerably branded by the process of "childhood re-institutionalization" (Sarmento, 2013): Childhood was brought to school, and school has been creating a regulation that reinforces some negative stigmas in children-the child still cannot, is not capable of, does not have the right to this or that. According to this perspective, one that we rebut, preschool education is understood as compensatory, capable of meeting children's incompletenesses. Other dilemma is 
related with our knowledge that educational policies for childhood, globally, are based on neoliberal hegemonic conceptions, which have been diversifying provision and contents of childhood education (Vilarinho, 2012; 2013; 2015), privileging a preschooling orientation, whilst our stance is bound to critical perspectives.

The contributions of social constructionism to childhood education (Katz, 1977; Vygotsky, 1998; Formosinho, Kishimoto, \& Pinazza, 2007; Hohmann, Banet, \& Weikart, 1992; Malaguzzi, 1999; Spodeck, 1982; Spodeck, Saracho, \& Davis, 1987; Moss, 2015; Vasconcelos, 2002) allow us to put into question, as well models of childhood education, making us adopt a stance that establishes the rights of children, warranted in the Convention on the Rights of the Child, grounded on the scientific studies carried out in this field, and that is in accordance with the international quality requirements, duly contextualized in the reality of São Tomé and Príncipe.

\section{Training Teachers-To Emancipation or to Reproduction of the Status Quo Utilitarianism?}

One other dilemma is related with our stance towards the training of teachers, and its congruence with the tenets of education (effectively in development and rhetorically desired). In the light of an emancipatory discourse, which advocates children's whole development, and prepares active and intervening citizens in the making of a developing country, we detected pedagogical interventions strictly preschooler, with a propaedeutic and immediatist nature.

In a short synthesis on the dilemmas that we are faced with, and based on our knowledge on the training of teachers, on which we have been reflecting in several of our texts (Sarmento, 2002; 2009a; 2009b), we are able to state that they have, as their starting point, taken into account our awareness on our own Eurocentric training and socialization and the risks of our not being able to completely strip ourselves of those references, in a way that should allow us to act in other context, characterized by its own values.

Other dilemma centered on childhood conceptions, on the ethical need for us to focus on the children of São Tomé and Príncipe and on their specific cultures. Finally, the relevance of an intervention on a training of teachers that is capable to be consistent and congruent with a creative and emancipatory preschool education.

\section{Managing the Dilemmas: A Collaborative Process of Construction}

From a critical reflection on these determining factors, in the process of policies making, we have, then, started to get familiar with the settings where our work was going to be realized, trusting in a participatory methodology, requesting an effective collaboration of the local actors. Thus, as the process is concerned, after we have carried out a documental analysis of the legal references and relevant studies: (1) We hold meetings with the leadership staff, to make a diagnosis of the situation and to define work methodologies; (2) We proceeded to a stage of observation of the different contexts; (3) We developed some "focus groups" with people and entities involved in the process (teachers, non-governmental organizations [ONGs], Caritas Internationalis, Misericórdia, social assistance, associations, federation of ONGs, and others); (4) We conducted a survey on the various entities which could become partners of the State in basic education; (5) We analyzed opportunities and constraints to an education communitarian movement; (6) We identified alternative models of childhood education, with children and their families; (7) We held periodical meetings with the different groups of actors, to realize a shared revision of the making of the legal framework; (8) We idealized the drafts of the Preschool Education Act of São Tomé and Príncipe and of the Statutes of Preschool Education Institutions of São Tomé and Príncipe; and (9) We 
realized a public presentation of these references, and finally, delivered them to the authorities that requested our work.

In a short notice to each one of these items, we should like to highlight the following: Our analysis to the documents allowed us to stress the purpose established in the Educational Policy Chart of promoting and expanding preschool education, in the light of its relevance to the developing of children, and also, of the country itself. The identification of this priority demands a huge expansion, and the local government agencies consider that it must be mandatory. Even though, for us, in our quality of European researchers, this obligatoriness is questionable, our contact with the reality of São Tomé and Príncipe has allowed us to understand that, in this context, this obligatory nature, implemented to children aged four years old and more, shall constitute itself a way of guaranteeing those children the universalization of the system, the opportunity of guaranteeing these children their integration in the system and their right to a daily hot meal.

The Education System Act of São Tomé and Príncipe (Act No. 2/2003-LBSE) warrants that "All of the citizens of São Tomé and Príncipe are entitled to education and culture, according to the wording of the Political Constitution (1st Paragraph, 2nd Article, 1st Chapter), being that principle understood as the foundation to promote a democratic society and warrant of an effective implementation of the right everyone must have to a fair equality of opportunities. According to Law of Education, issued in 2003, preschool education is optional, and it is directed to all children aged from zero to six years old, being up to the State to, through the Ministry of Education, Culture and Science (MECS) to assume the responsibility of the definition, creation, regulation, and follow-up of this educational level. Despite its optional nature, the successive governments of São Tomé and Príncipe have been showing an increasing interest in the enlargement of the number of children benefited by preschool education and in the improvement of the quality of the attendance provided to children. The "Chart of Education Policy: Policies and Development Strategies until 2022” (1st edition of 2012) ${ }^{2}$ presents a relevant analysis on the demographic, social, economic, and educational situation in São Tomé and Príncipe and suggests policies and development strategies for the field of education. São Tomé and Príncipe is a country with a very young population (children represent 55\% of the population), going through a growing poverty situation (1994 is $40 \%$; while 2010 is $60.2 \%$ ). A situation of extreme poverty affects $15 \%$ of the population, of whom $44 \%$ live according to very low standards of comfort, and only $15 \%$ of them live in a more or less moderate level of comfort. The rate of literacy is of $45.9 \%$, and the rate of global attendance of the educational system of $45 \%$ (Institute National of Statistics-SãoTomé Príncipe, 2013).

The system of preschool education is poorly developed, with only 1/3 of the children of São Tomé and Príncipe enrolling in this cycle of studies (0-5 years old), representing the children aged from 3-5 years $54 \%$ of that rate (Chart of Education Policy: Policies and Development Strategies until 2022). Classrooms are populated by an average number of 68 children, and there is a scarcity of pedagogical materials, with an educator with the task of coordinating the institution, although the children were being taken care by auxiliary staff, who have a low professional recognition, both at the level of their social status, and at the level of their remuneration status, and manifesting difficulties of cooperation among the different entities, which creates obstacles to the making of strategic thinking leading to action.

In the meetings held with the different groups of local actors, we started by addressing educational, social, and organizational conceptions, aspects relating with children's day to day, as well as conceptions relative to

${ }^{2}$ Chart of Education Policy: Policies and Development Strategies until 2022 (2012). 
profiles, training and professional questions. The first meetings allowed us to get to know the existing perspectives, sensibilities and expectations relating to the enlargement of the network of preschool education and to the re-qualification of the services provided; to identify opportunities and constraints, and to detect some difficulties that must be overcome in a collaborative fashion, after a thorough local debate is carried out on what should be understood by education, children, and rights, inclusive society and articulation between educational policies and social policies.

From our reflection upon this first stage, we identified three axes to be considered in the conception of the legal framework, namely:

1. At the level of the network-the reorganization of the sub-levels that were created (0-3/3-5) and the enlargement of the services provision;

2. At the level of the conception - the clarification of the social-educational guidance, the articulation with the 1st Cycle of Basic Education and with the families;

3. At the organizational level—the promotion of quality, the implementation of new modalities of services, and the regulation, monitoring, and inspection of the system.

From that point onwards, the grounds for the definition of preschool education in São Tomé and Príncipe were locally identified and discussed, integrating the recognition of everybody's rights, those of both children and their families, the implementation of a preschool education of high quality, based on integrated policies directed towards childhood (Sarmento, 2013; Vilarinho, 2013), in a developing country, which are capable of building bridges with the field of health, with the field of social assistance, and with the field of the law. Other ground that was defined was the relevance of the creation alternate modalities, which are able of taking into consideration the demographic and morphologic diversity of the country, either modalities that develop into communitarian centers, or into ambulatory education, or into kindergartens.

\section{Conclusion}

Summarily, we can state that, as a result of the work carried out in tight cooperation with the official entities and the various local agents, and after identification of the strengths and weaknesses of the Preschool Education System of São Tomé and Príncipe, in articulation with the analysis of the different literature sources on the reality of São Tomé and Príncipe and with our scientific knowledge in the field of childhood education, it was possible to make a proposal which defined the priorities, the goals, and the definitions of the political strategies.

Thus, our study on the reality of the country, and the whole process, previously lived and described, allowed us to little by little identify and construct, in a participatory fashion, the large lines of the definition of the Preschool Education Act and of the Statutes of Preschool Educations, namely, in what concerns their political, epistemological, pedagogical grounds, and their organizational tenets.

In the making of the already mentioned legal diplomas, we have paid attention to the following foundations:

1. The Democratic Republic of São Tomé and Príncipe acknowledges every child's rights to education and to child well-being;

2. A good quality preschool education warrants the equality of educational opportunities for all children;

3. Preschool education is essential to the integral development of children;

4. Preschool education and the training of its professionals are shaped by international scientific knowledge;

5. Preschool education is the first stage of basic education;

6. Preschool education is developed in a diversity of educational contexts and of pedagogical models; 
7. Preschool education is developed in articulation with families;

8. Preschool education is developed on the basis of integrated policies for childhood;

9. Preschool education mobilizes the participation of local entities and actors;

10. Preschool education takes place within the community and promotes local development.

Concluding, we reaffirm that we recognize the essential role of the State as warrant of the right of the children of São Tomé and Príncipe to a good quality preschool education, even though with the collaboration of non-profit actors of the civil society.

\section{References}

Barroso, J. (2003). Regulation and deregulation in education policies: Emerging trends in comparative education studies. In J. Barroso (Org.), Public school, regulation, deregulation, and privatization (pp. 19-48). Porto: ASA Edições. (in Portuguese)

Bourdieu, P., \& Passeron, J. C. (1978). Reproduction elements for a theory of the education system. Lisboa: Editorial Veja. (in Portuguese)

Bowe, R., Ball, S. J., \& Gold, A. (1992). The policy process and the process of policy. In R. Bowe \& S. J. Ball (Eds.), Reforming, education and changing schools. The use case studies in policy sociology (pp. 6-23). Londres: Routledge.

Dale, R. (1998). Education and the capitalist state: Contributions and contradictions. Education and Reality, 13(1), 17-37. (in Portuguese)

Corsaro, W. (1997). The sociology of childhood. Thousand Oaks: Pine Forge Press.

Government STP. (2012). Letter of education policy: Policy and development strategies in horizon 2022. (in Portuguese)

Formosinho, J. O., Kishimoto, T. M., \& Pinazza, M. A. (2007). Pedagogie(s) childhood-Dialoguing with the past: Building the future. Cadernos de Pesquisa, 36(129), 519-546. (in Portuguese)

Hohmann, M., Banet, B., \& Weikart, D. P. (1992). The child in action. Lisboa: Fundação Calouste Gulbenkian. (in Portuguese)

Institute National of Statistic. (2013). Data Dissemination Seminar-IV General Census of Population and Housing 2012 (RGPH-2012). São Tomé 25 de Setembro. (in Portuguese)

James, A., Jenks, C., \& Prout, A. (1998). Theorizing childhood. Polity Press: Cambridge.

Katz, L. (1977). Talks with teachers: Reflections on early childhood education. Illinois: National Association for the Education of Young Children.

Malaguzzi, L. (1999). The hundred languages of children. Porto Alegre: Artmed. (in Portuguese)

Ministério da Educação, Cultura e Formação (2012). Education policy letter of Sao Tome and Principe (Visão 2022). (in Portuguese)

Moss, P. (2015). Childhood, education, and society at a time of deepening multiple crises. SPCE, Revista Investigar em Educação: Infância(s), Educação e Sociedade, (4), 9-23.

Prout, A. (2010). Reconsider new sociology of childhood: For an interdisciplinary study of children. Cadernos de Pesquisa, 40(141), 729-750. Retrieved from http://www.scielo.br/pdf/cp/v40n141/v40n141a04.pdf (in Portuguese)

Qvortrup, J. (1991). Childhood as a social phenomenon-An introduction to a series of national reports (Eurosocial Report No. 36). Vienna: European Centre.

Qvortrup, J. (2010). The temptation of diversity and its risks. Educação e Sociedade, 31(113), 1121-1136. (in Portuguese)

Sanches, M. (Org.). (2012). Meshes empires weave anti-colonial texts, postcolonial contexts. Lisboa: Edições 70. (in Portuguese)

Santos, B. S. (2004). Post-modern to post-colonial and apart from one another. Retrieved from http://www.ces.uc.pt/misc/Do_ posmoderno_ao_pos-colonial.pdf (in Portuguese)

Santos, B. S. (2010). In addition to the abyssal thinking: The global lines to an ecology of knowledge. In B. S. Santos \& M. P. Meneses (Orgs.), Epistemologias do Sul (pp. 31-83). São Paulo: Cortez. (in Portuguese)

Sarmento, M. (2003). What fits in hand-Propositions for an integrated policy for children. In D. Rodrigues (Org.), Perspectivas Sobre a Inclusão. Da Educação à Sociedadez (pp. 73-85). Porto: Porto Editora. (in Portuguese)

Sarmento, M. (2013). The sociology of childhood and contemporary society: Conceptual and praxeological challenges. In R. Ens \& M. Garanhani (Orgs.), Sociologia da infância e formação de professores (pp. 13-46). Curitiba: Champagnat Editora. (in Portuguese)

Sarmento, T. (2002). Childhood educators life stories. Lisboa: Col. Ciências da Educação. (in Portuguese)

Sarmento, T. (2009a). The professional identities in childhood education. Revista Locus SOCI@L, 2, 46-64. (in Portuguese) 
Sarmento, T. (2009b). Contexts of life and learning job. In J. Formosinho (Org.), Sistemas de formação de professores: Saberes docentes, aprendizagem profissional e aç̧ão docente. Porto: Porto Editora. (in Portuguese)

Spodeck, B. (1982). Handbook of research in early childhood education. New York, N.Y.: Free Press.

Spodeck, B., Saracho, O. N., \& Davis, M. D. (1987). Foundations of early childhood education. Englewood Cliffs, N.J.: Prentice-Hall.

Vasconcelos, T. (2002). Around the large table: The educational practice of Ana. Porto: Porto Editora. (in Portuguese)

Vilarinho, E. (2012). Pre-school education policies and partnerships between the State and the Third Sector. Configurações, 10, 109-122. (in Portuguese)

Vilarinho, E. (2013). The right of children to education quality public preschool: A critical review of the implementation of the education and child care model in Portugal. Revista Pedagógica, Chapecó, 15(31), 281-300. (in Portuguese)

Vilarinho, E. (2015). The “cause” of pre-school education in Portugal: Approaches to Third Way policies. In V. M. V. Peroni (Org.), Dialogues on the redefinitions in the role of the state and the boundaries between public and private in education (pp. 144-174). São Leopoldo: Oikos. (in Portuguese)

Vygotsky, L. S. (1998). Dialogues on the redefinitions in the role of the state and the boundaries between public and private in education. São Paulo: Martins Fontes. (in Portuguese)

Walford, G. (2001). Privatization in industrialized countries. In H. Levin (Ed.), Privatizing education can the marketplace deliver choice, efficiency, equity, and social cohesion?. Colorado, USA: Westriew Press. (in Portuguese) 